\title{
Dipeptide Synthesis from S-2-Formyl-4-Nitrophenyl Thioesters and Amino Acid Salts
}

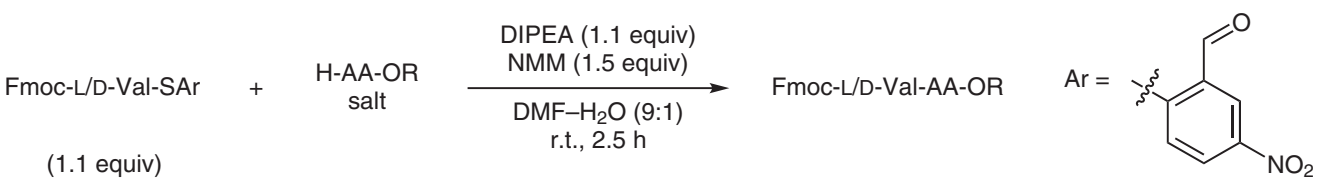

dipeptides

formyl nitrophenyl

thio esters

methylmaleimide

1,4-addition

chemoselectivity

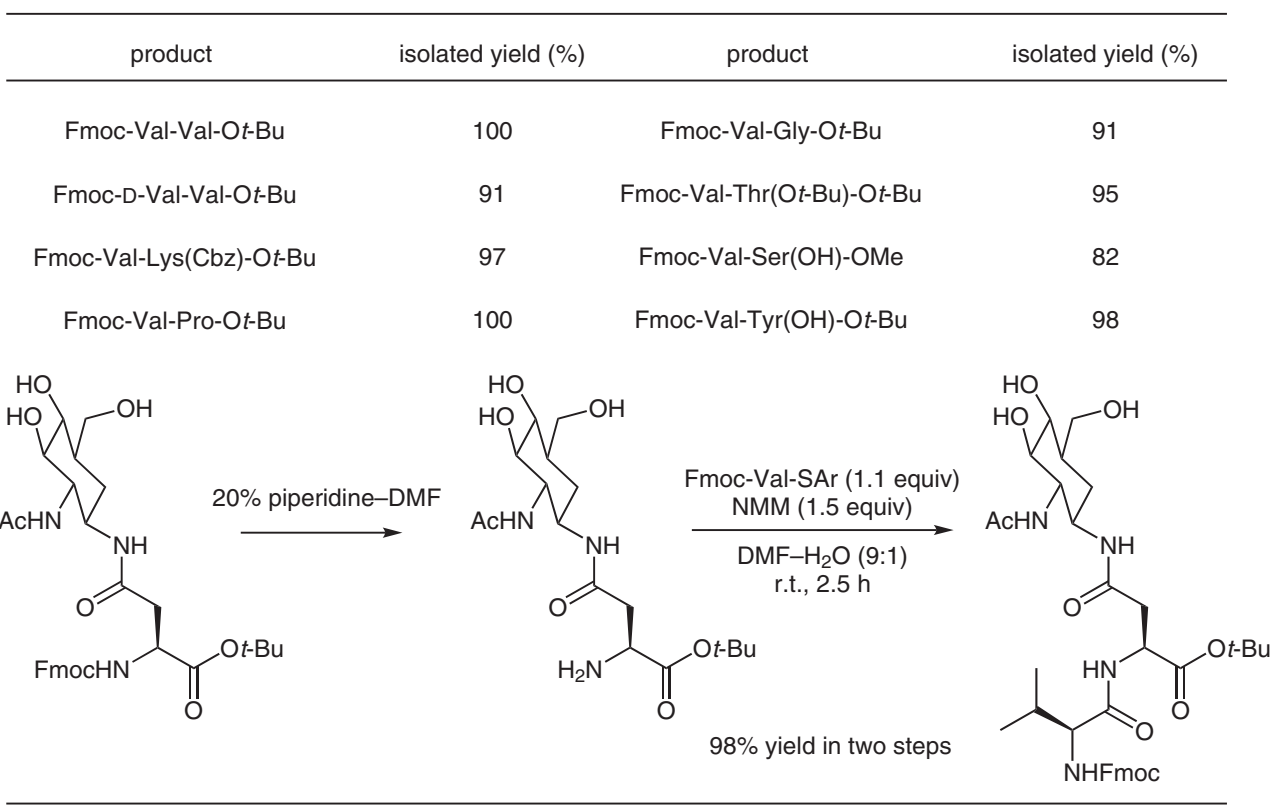

Proposed mechanism:<smiles>CCOC(=O)C(N)C(C)C</smiles>

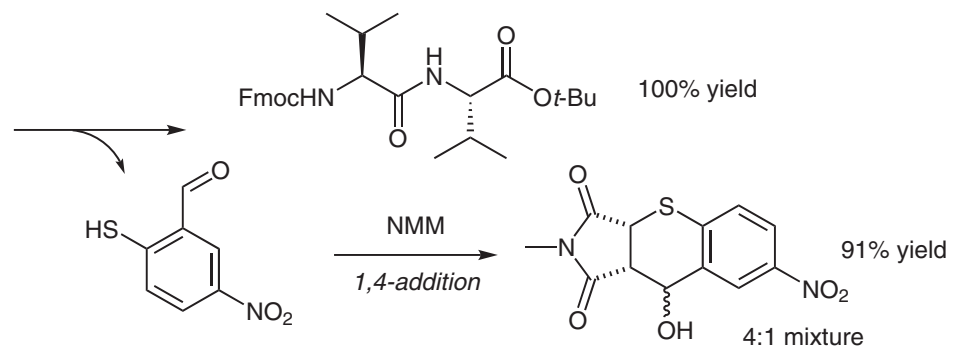

Significance: Amide bond formation is very significant in peptide chemistry, and many approaches have been developed to form the peptide bonds. The authors used formyl-substituted S-4-nitrophenyl thioesters to synthesize dipeptides. The reaction could be conducted in the presence of water.
Comment: A broad variety of dipeptides can be synthesized from S-2-formyl-4-nitrophenyl thioesters and amino acid salts. $\mathrm{N}$-Methylmaleimide is used to trap the resulting thiophenol to improve the final yield. The yields of the reactions are good to excellent. 